\title{
Solvent Effects in Radical Copolymerization between Hydrophilic and Hydrophobic Monomers; 2-Hydroxyethyl Methacrylate and Lauryl Methacrylate
}

\author{
Koichi ITO, Koji UCHIDA, ${ }^{\dagger}$ Toshiaki KITANO, \\ Eiichi YAMADA, ${ }^{*}$ and Takeo MATSUMOTO* \\ School of Materials Science, Toyohashi University of Technology, \\ Tempaku-cho, Toyohashi 440, Japan \\ *Tsukuba Laboratory, Nippon Oil \& Fats Co., Ltd., Tokodai 5-10, \\ Toyosato-cho, Tsukuba, Ibaragi 300-26, Japan
}

(Received September 26, 1984)

\begin{abstract}
The radical copolymerization of 2-hydroxyethyl methacrylate (HEMA, $\left.\mathrm{M}_{1}\right)$ and lauryl methacrylate $\left(\mathrm{LMA}, \mathrm{M}_{2}\right.$ ) was investigated at $60^{\circ} \mathrm{C}$ with $\mathrm{AIBN}$ in various solvents including benzene, tetrahydrofuran, tert-butylalcohol, and dimethylformamide. HEMA was found to have an abnormally high, apparent monomer reactivity ratio in benzene, $r_{1}=11.2$, corresponding to its high aggregation tendency in this solvent as a result of hydrogen-bonding. The apparent reactivity ratios are more or less close to azeotropic unity in the other solvents. The solution behavior of monomers is proposed as a factor in the copolymerization between hydrophilic and hydrophobic monomers.
\end{abstract}

KEY WORDS Solvent Effect / Radical Copolymerization / 2-Hydroxyethyl Methacrylate / Lauryl Methacrylate / Hydrophilic-Hydrophobic Copolymers / Hydrogen-Bonding Aggregation / Monomer Reactivity Ratio /

Increasing attention is currently being directed to the synthesis of copolymers carrying both hydrophilic and hydrophobic segments for application to various functional polymers. This trend is further stimulated by the recent development of the macromonomer ('macromer') technique for preparing well-defined graft copolymers. The copolymerization between hydrophilic and hydrophobic monomers, however, involves certain complications arising from the very different solution properties of the monomers. In fact, acid monomers such as acrylic acid and methacrylic acid have been found to have apparently higher reactivities in copolymerizations with methyl methacrylate or styrene in nonpolar solvents compared to those in polar solvents. ${ }^{1-6}$ This is accounted for by aggregation of the acid monomers through hydrogen-bonding. Selective solvation of a growing chain end by the acid monomer was proposed by Plochocka and Harwood ${ }^{5}$ for styrene-acrylic acid system based on the fact that the monomer sequence (triad) distribution, determined by $300 \mathrm{MHz}{ }^{1} \mathrm{H} \mathrm{NMR}$, was found to be the same for copolymers of the same composition, irrespective of the solvents used in the preparation.

2-Hydroxyethyl methacrylate (HEMA) is widely used as a typical hydrophilic monomer with a nonelectrolytic hydroxyl group. Although its copolymerization has been reported in a limited cases, ${ }^{7-14}$ the available monomer reactivity ratios are somewhat mis-

\footnotetext{
${ }^{\dagger}$ Present Address: Aicello Chemical Co., Ltd., Ishimaki, Toyohashi 440, Japan.
} 
K. ITo et al.

Table I. Selected radical-copolymerization parameters of HEMA

\begin{tabular}{|c|c|c|c|c|c|}
\hline $\mathrm{M}_{1}$ & $\mathrm{M}_{2}$ & Conditions & $r_{1}$ & $r_{2}$ & Ref \\
\hline HEMA & $\mathrm{MMA}^{\mathrm{a}}$ & $\mathrm{BPO}$, bulk, $60^{\circ} \mathrm{C}$ & 1.054 & 0.296 & 7 \\
\hline HEMA & $\mathrm{MMA}^{\mathrm{a}}$ & $\begin{array}{l}\text { AIBN, DMF }([M]=0.3 \\
\left.\mathrm{moll}^{-1}\right), 60^{\circ} \mathrm{C}\end{array}$ & 0.66 & 0.84 & 8 \\
\hline HEMA & $\mathrm{MMA}^{\mathrm{a}}$ & - & 1.25 & 0.89 & 9 \\
\hline HEMA & $\mathrm{MMA}^{\mathrm{a}}$ & Calcd from $Q, e$ & 1.18 & 0.85 & 10 \\
\hline HEMA & $\mathrm{St}^{\mathrm{b}}$ & AIBN, bulk, $60^{\circ} \mathrm{C}$ & 0.85 & 0.33 & 8 \\
\hline HEMA & $\mathrm{St}^{\mathrm{b}}$ & - & 0.65 & 0.57 & 9 \\
\hline HEMA & $\mathrm{St}^{\mathrm{b}}$ & Calcd from $Q, e$ & 0.65 & 0.56 & 10 \\
\hline HEMA & $\mathrm{SMA}^{\mathrm{c}}$ & $\begin{array}{l}\text { AIBN, THF }([\mathrm{M}] \cong \\
\left.40 \mathrm{wt}^{\circ} \%\right), 60^{\circ} \mathrm{C}\end{array}$ & 3.02 & 0.76 & 11 \\
\hline HEMA & PSt-MA $^{d}$ & $\begin{array}{l}\text { AIBN, DMF, }([\mathrm{M}]= \\
\left.10 \mathrm{wt}^{\circ} \%\right), 60^{\circ} \mathrm{C}\end{array}$ & $1.7 \pm 0.4$ & - & 12 \\
\hline HEMA & PSt-MA ${ }^{\mathrm{e}}$ & $\begin{array}{l}\mathrm{DIPC},{ }^{\mathrm{f}} \mathrm{DMF}([\mathrm{M}] \cong \\
\left.20 \mathrm{wt}^{\circ} \%\right), 60^{\circ} \mathrm{C}\end{array}$ & $2.0-2.3$ & - & 13 \\
\hline
\end{tabular}

a Methyl methacrylate. ${ }^{\mathrm{b}}$ Styrene. ${ }^{\mathrm{c}}$ Stearyl methacrylate.

d Methacrylate-ended polystyrene, $M_{n}=3180$.

e Methacrylate-ended polystyrene, $M_{n}=14000$ or 23000 .

f Diisopropyl peroxydicarbonate.

leading in that they significantly differ depending on the authors and/or conditions, as exemplified in Table I. This fact by itself suggests the complicated nature of the copolymerization including HEMA. A similar complication was recently found for the rate of copolymerization of HEMA with styrene. ${ }^{15}$

To understand the abnormal behavior of HEMA, we examine in this paper copolymerization with a typical hydrophobic monomer, lauryl methacrylate (LMA) in various solvents, together with some physico-chemical properties of the monomers. The results are discussed in terms of possible factors influencing the copolymerization between hydrophilic and hydrophobic monomers.

\section{EXPERIMENTAL}

Monomers, HEMA and LMA, were distilled over calcium hydride under a reduced pressure of argon. Solvents were purified and distilled by usual procedures. $\alpha, \alpha^{\prime}$-Azobisisobutyronitrile (AIBN) was recrystallized from methanol.

Copolymerization was conducted in a flask equipped with a three-way cock with a silicone septum. Monomers, AIBN, solvent, and nonadecane, which served as an internal standard for gas chromatography, were charged into the flask, degassed by freeze-thaw cycles, charged with argon gas, and then placed in an oil bath at $60 \pm 1^{\circ} \mathrm{C}$. Consumption of the monomers was monitored by a gas chromatograph, Yanaco G-180, equipped with a column of PEG 20M, 2.25 or $3 \mathrm{~m}$ length, and a TCD or FID detector. The column temperature was 190 or $200^{\circ} \mathrm{C}$. Copolymer compositions were calculated from the monomer concentration-time plots at a point of about $10 \%$ total conversion so as to avoid any ambiguity in the reading of the consumption rate at zero conversion. The copolymerization system was homogeneous up to this conversion in all cases investigated.

Some copolymers were prepared independently under the same conditions, precipitated out of a mixture of water and methanol $(20: 80, \mathrm{v} / \mathrm{v})$, and dried in vacuo. ${ }^{1} \mathrm{H}-\mathrm{NMR}$ spectra were recorded on a JEOL JNM-PMX 60 spectrometer, and gel permeation chromatography (GPC) was carried out on a JASCO 
TRIROTAR-III equipped with a column A803 with a tetrahydrofuran solution at a flow rate of $1 \mathrm{ml} \mathrm{min}^{-1}$ at $40^{\circ} \mathrm{C}$, monitored by a RI detector, Shodex SE-11.

The freezing point of a monomer solution for cryoscopic determination of aggregation was read on a cooling-curve (temperaturetime plot) made with a mechanically stirred solution in a double-wall glass tube cooled outside with a dry ice-acetone mixture. The temperature was read with a standardized thermometer inserted into the solution. Heat of solution was measured on a twin calorimeter, TIC-2D, Tokyo Riko Co., Ltd., at a molar ratio of monomer to solvent greater than 150 as an approximation of infinite dilution. Temperature of measurement was $20.5^{\circ} \mathrm{C}$ in benzene, tetrahydrofuran (THF), and dimethylformamide (DMF), and $26.0^{\circ} \mathrm{C}$ in tert-butylalcohol $\left({ }^{t} \mathrm{BuOH}\right)$. The error of the measurement was estimated to be within $\pm 5 \%$.

\section{RESULTS AND DISCUSSION}

The copolymerization of HEMA and LMA was conducted at $60^{\circ} \mathrm{C}$ with AIBN, at a total monomer concentration of $0.5 \mathrm{~mol}^{-1}$ in benzene, THF, ${ }^{t} \mathrm{BuOH}$, and DMF. Figure 1 shows the monomer-copolymer composition curves obtained by monitoring the monomer consumption by gas chromatography. Clearly, the reactivity of HEMA is abnormally high in benzene, while the compositions are more or less close to the azeotrope line in the other solvents. Monomer reactivity ratios were estimated by the method of Kelen and Tüdös, ${ }^{16}$ and the results are given in Table II. Here again, HEMA is highly reactive, with $r_{1}$ amounting to 11.2 , while the reactivity ratios in the other solvents are scattered around unity. It should be noted that the composition curves in Figure 1 as well as the Kelen-Tüdös plots were normal in all cases, thus apparently fitting the conventional, terminal copolymerization model.

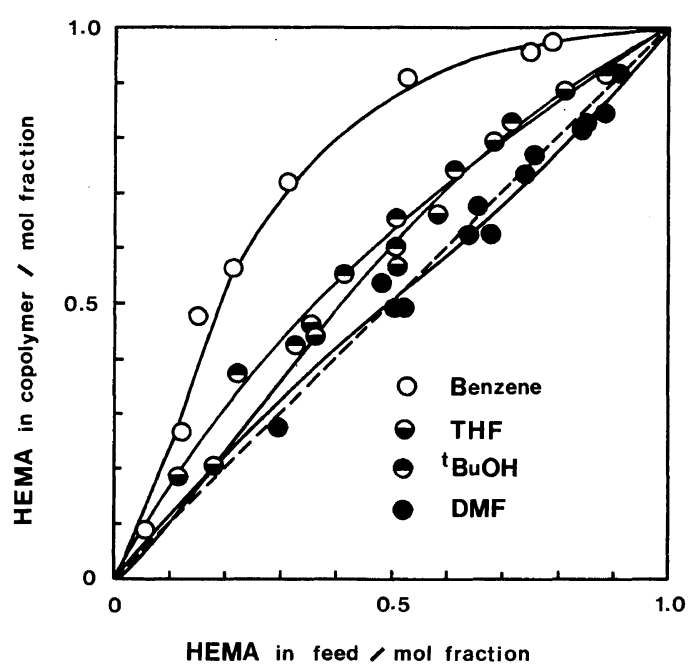

Figure 1. Composition curves for copolymerizations of HEMA and LMA in various solvents. Total monomer concentration $=0.5 \mathrm{~mol} \mathrm{l}^{-1}$.

Table II. Monomer reactivity ratios of copolymerizations of HEMA $\left(\mathrm{M}_{1}\right)$ and LMA $\left(\mathrm{M}_{2}\right)$ in various solvents ${ }^{\mathrm{a}}$

\begin{tabular}{lrc}
\hline Solvent & \multicolumn{1}{c}{$r_{1}$} & \multicolumn{1}{c}{$r_{2}$} \\
\hline Benzene & $11.2 \pm 2.8$ & $0.7 \pm 0.3$ \\
THF & $2.0 \pm 0.3$ & $1.0 \pm 0.3$ \\
${ }^{t} \mathrm{BuOH}$ & $1.6 \pm 0.3$ & $0.5 \pm 0.2$ \\
$\mathrm{DMF}$ & $0.8 \pm 0.1$ & $0.8 \pm 0.4$ \\
\hline
\end{tabular}

a Errors indicated are $95 \%$ confidence limits.

Some copolymers were independently prepared, isolated, and characterized by ${ }^{1} \mathrm{H}$ NMR and GPC, and the results are summarized in Figure 2 and Table III. These copolymers were all soluble in chloroform, a nonsolvent for a HEMA homopolymer. The NMR spectrum in $\mathrm{CDCl}_{3}$ showed slightly sharper peaks of lauryl methylene and $\omega$-methyl protons, at $\delta 1.2$ and 1.0, respectively, compared to those of HEMA oxyethylene protons at about $\delta 4.0$, while exactly the reverse trend was observed in a spectrum in a mixture of $\mathrm{CDCl}_{3}$ and $\mathrm{CD}_{3} \mathrm{OD}(1: 1$, $\mathrm{v} / \mathrm{v})$. This indicates that LMA units constitute a relatively more mobile segment in the former solvent, while HEMA units do so in the latter solvent. The peak areas, however, are normal in that the copolymer compositions estimated 
K. Iто et al.

Table III. Characterization of HEMA $\left(\mathrm{M}_{1}\right)$-LMA $\left(\mathrm{M}_{2}\right)$ copolymers

\begin{tabular}{|c|c|c|c|c|c|c|c|c|}
\hline \multirow{3}{*}{$\begin{array}{c}\text { Polymn. } \\
\text { solvent }\end{array}$} & \multirow{3}{*}{$\begin{array}{c}\text { HEMA } \\
\text { mol } \% \\
\text { in } \\
\text { feed }\end{array}$} & \multicolumn{2}{|c|}{ Polymn. } & \multicolumn{3}{|c|}{ HEMA $\mathrm{mol} \%$ in copolymer } & \multirow{2}{*}{\multicolumn{2}{|c|}{$\begin{array}{l}\text { GPC data } \\
\quad \text { (rel to PSt) }\end{array}$}} \\
\hline & & \multirow{2}{*}{$\begin{array}{l}\text { time } \\
\min \end{array}$} & \multirow{2}{*}{$\begin{array}{c}\text { Yield } \\
w t \%\end{array}$} & \multirow{2}{*}{$\begin{array}{l}\text { Calcd } \\
\text { from } \\
r_{1}, r_{2}\end{array}$} & \multicolumn{2}{|c|}{ from NMR in } & & \\
\hline & & & & & $\mathrm{CDCl}_{3}$ & $\begin{array}{r}\mathrm{CDCl}_{3} \\
+\mathrm{CD}_{3} \mathrm{OD}\end{array}$ & $M_{n} \times 10^{4}$ & $M_{w} / M_{n}$ \\
\hline Benzene & 10 & 60 & 9 & 22 & 15 & - & - & - \\
\hline Benzene & 20 & 35 & 15 & 50 & 48 & 45 & 4.2 & 1.8 \\
\hline Benzene & 33 & 21 & 17 & 75 & 76 & - & 3.9 & 2.2 \\
\hline THF & 39 & 46 & 14 & 47 & 43 & 49 & 2.3 & 2.5 \\
\hline${ }^{t} \mathrm{BuOH}$ & 37 & 20 & 7 & 50 & 41 & 37 & 4.3 & 2.0 \\
\hline DMF & 50 & 11 & 19 & 50 & 41 & 40 & 2.2 & 2.5 \\
\hline
\end{tabular}

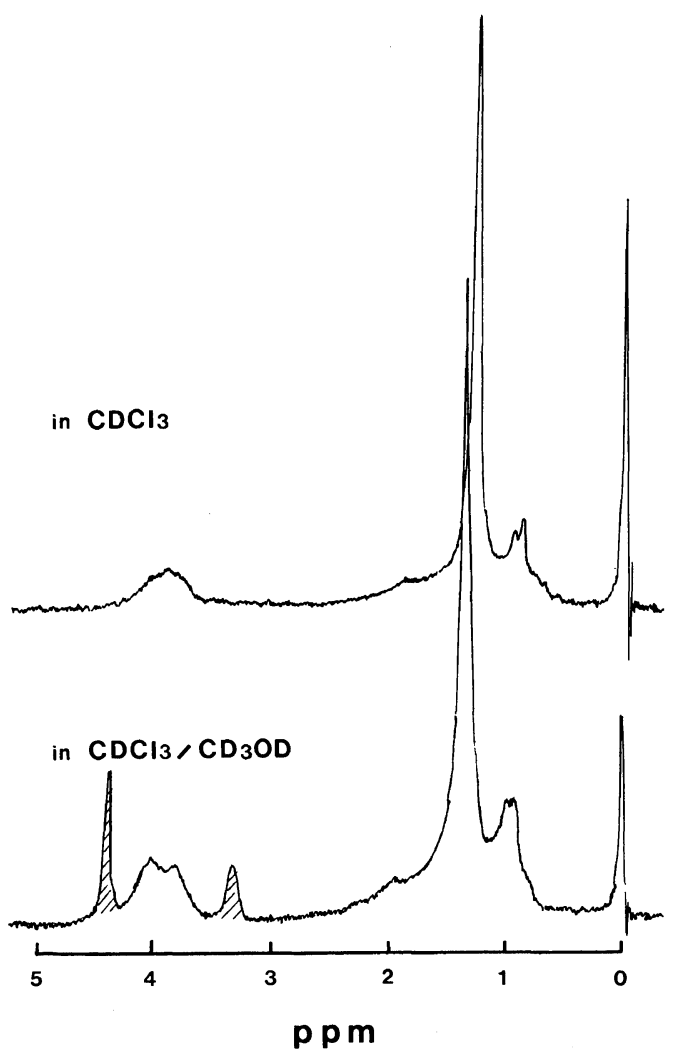

Figure 2. ${ }^{1} \mathrm{H}$ NMR spectra of a HEMA-LMA copolymer (from copolymerization in benzene at a molar ratio $\mathrm{HEMA} / \mathrm{LMA}=20 / 80$ ) in $\mathrm{CDCl}_{3}$ and in $\mathrm{CDCl}_{3}-\mathrm{CD}_{3} \mathrm{OD}(1: 1, \mathrm{v} / \mathrm{v})$.

from the relative areas of the respective peaks were the same, irrespective of the solvents for the NMR measurements. ${ }^{18}$ This is in sharp contrast with the fact that, for polyHEMA-

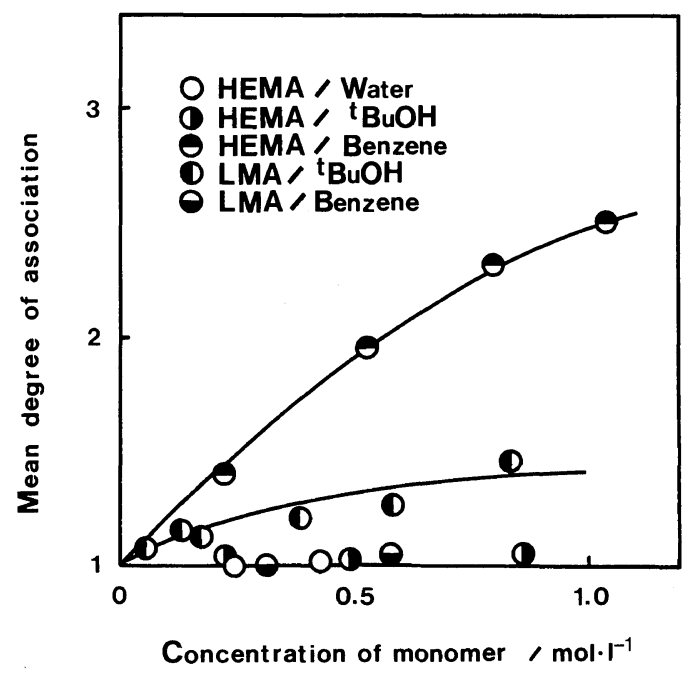

Figure 3. Mean degree of association of HEMA and LMA in various solvents.

polystyrene graft copolymers, the peak of HEMA oxyethylene protons was absent in the spectrum, possibly as a result of a micelle formation with a core of HEMA segments in chloroform. ${ }^{12}$ All these observations clearly support that the HEMA-LMA copolymers are qualitatively random in sequence distribution. No difference was also found in the ${ }^{1} \mathrm{H}$ NMR spectra of the copolymers in Table III, depending on the solvent for copolymerization.

The apparently high reactivity of HEMA suggested an aggregation of this monomer in benzene, and thus some physico-chemical properties were examined. Figure 3 shows the 


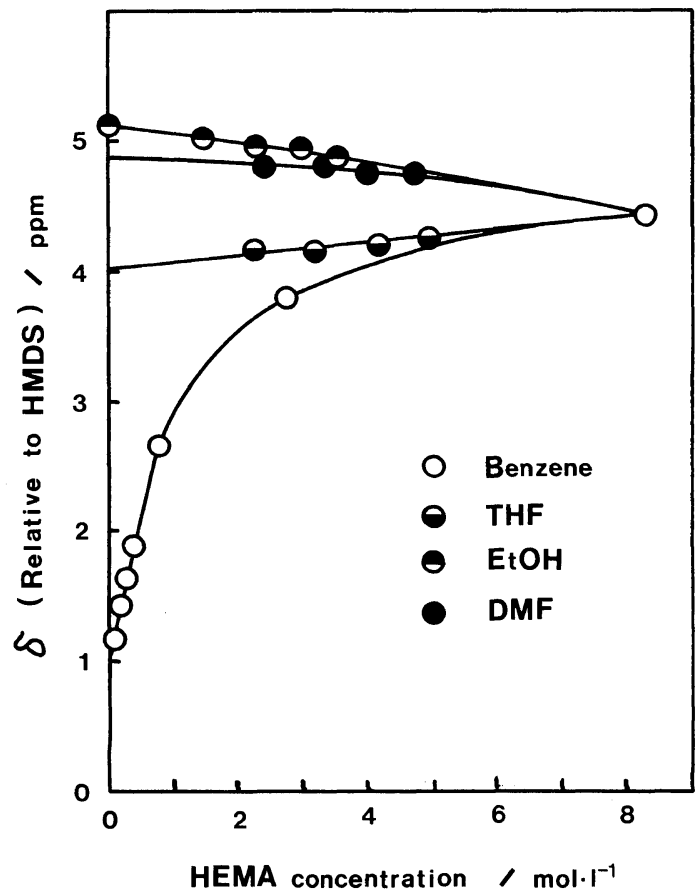

Figure 4. Hydroxyl proton chemical shifts of HEMA in various solvents.

mean degree of association of the monomers, estimated cryoscopically. As expected, HEMA is clearly aggregated in benzene, while no association was found in water and in ${ }^{t} \mathrm{BuOH}$. In contrast, LMA shows some degree of association in the polar solvent, ${ }^{t} \mathrm{BuOH}$, but no association in benzene. The HEMA hydroxyl chemical shift in Figure 4 shows a very pronounced shift in benzene to a lower magnetic field with increasing concentration as compared to very small, linear shifts in the other solvents. This strongly supports the intermolecular aggregation of HEMA as a result of hydrogen-bonding. Heats of solution, $\Delta H$, of HEMA and LMA in the four solvents were measured by a twin calorimeter. The data in Table IV indicate a considerably high endothermic process of HEMA dissolved into benzene, supporting a corresponding high aggregation energy in this system. Relatively small values of $\Delta H$ in cases including HEMA in ${ }^{t} \mathrm{BuOH}$ and in DMF, and LMA in benzene and in THF indicate no particular interactions
Table IV. Heat of solution of HEMA and LMA in various solvents

\begin{tabular}{lcc}
\hline & \multicolumn{2}{c}{$\Delta H, \mathrm{kcal} \mathrm{mol}^{-1 \mathrm{~b}}$} \\
\cline { 2 - 3 } Solvent $\left(\varepsilon^{\mathrm{a}}\right)$ & HEMA & LMA \\
\hline Benzene (2.28) & 2.7 & 0.78 \\
THF (7.58) & -0.053 & 0.41 \\
${ }^{t}$ BuOH (12.5) & 0.19 & 2.7 \\
DMF (36.7) & -0.78 & 2.6
\end{tabular}

a Dielectric constant at $25^{\circ} \mathrm{C}$.

b Negative values indicate exothermic heats of solution.

in these systems. LMA, when dissolved in ${ }^{t} \mathrm{BuOH}$ and $\mathrm{DMF}$, shows a rather high $\Delta H$, suggesting again some association, possibly due to van der Waals attraction between the long alkyl groups in these polar solvents.

By the above results, it is reasonable that the apparently high reactivity of HEMA in benzene results from the high tendency of aggregation in this system. The value of $r_{1}$ in benzene, however, is larger than those in the other solvents by a factor of 6 to 13 , which is considerably higher than the mean degree of aggregation of HEMA, about 2.0 at $0.5 \mathrm{~mol}$ $1^{-1}$. Therefore, the increase in $r_{1}$ cannot be simply attributed to the increased local concentration as a result of only aggregation. Preferential solvation of the hydrophilic monomer around the active polymer radical, as proposed by Plochocka and Harwood, ${ }^{5}$ is also a plausible explanation for the result. In spite of some association of LMA observed in ${ }^{t} \mathrm{BuOH}$ and also possibly in DMF, $r_{2}$ values in Table II changed little with the solvent. The van der Waals interaction between the long alkyl groups may be relatively loose, long-ranged, and transient in nature, thus contributing little to the increase in local concentration of the double bonds or it may even lead to reduced reactivity of the double bond by making a hydrophobic environment or a steric repulsion about the reaction center. However, it is difficult to discuss further the respective values of $r_{1}$ and $r_{2}$ as well as the fact that the product $r_{1} r_{2}$ is 
greater than unity, unusual for a radical copolymerization, in THF, a solvent with little specific interaction with and among the monomers.

At any rate, the monomer reactivity ratios in these systems do not necessarily have true meaning as defined by $r_{1}=k_{11} / k_{12}$ and $r_{2}=k_{22} /$ $k_{21}$, but should be taken as apparent ratios subject to change in local concentration and/or in reactivity of the double bond, depending on the condition. This situation may be, at least in part, responsible for the varying monomer reactivity ratios reported by different authors for the same nominal system. Copolymerization in bulk or in a concentrated solution, particularly in nonpolar solvents, may be further complicated by possible change in aggregation and reactivity depending on feed composition. Evaluation of $r_{1}$ and $r_{2}$ from the $Q-e$ scheme would be almost meaningless in these systems.

The reactivity ratio of HEMA in copolymerization with methacrylate-ended polystyrene macromonomer $\left(r_{1}=1.7\right.$ or $2.0-2.3$ in DMF, Table I $)^{12,13}$ is higher than that with a model monomer LMA $\left(r_{1}=0.8\right.$ in DMF, Table II), indicating reduced reactivity of the macromonomer compared to the model monomer. This suggests some additional factor in copolymerization involving a macromonomer. Repulsive interaction between different polymers ${ }^{17}$ (polyHEMA radical and polystyrene macromonomer in this case) may possibly be such a factor.

In conclusion, copolymerization between HEMA and LMA was investigated in terms of solvent effects on the apparent monomer reactivity ratios, and discussed based on the solution properties of the monomers. Aggregation of hydrogen-bonding monomers in nonpolar solvents may be largely responsible for their increased reactivities.

Acknowledgements. The authors are greatly indebted to Dr. Kazuo Tsutsumi, Toyohashi University of Technology, for the use of a twin calorimeter. This work was supported in part by a fund from Nippon Oil \& Fats Co., Ltd.

\section{REFERENCES AND NOTES}

1. G. Merkert and H. Pennewiss, Angew. Makromol. Chem., 11, 52 (1970).

2. R. Kerber, Makromol. Chem., 96, 30 (1966).

3. R. Kerber and H. Glamonn, Makromol. Chem., 100, 290 (1967).

4. R. Kerber and H. Glamonn, Makromol. Chem., 144, 1 (1971).

5. K. Plochocka and H. J. Harwood, Polym. Prepr., Am. Chem. Soc., Div. Polym. Chem., 19(1), 240 (1978).

6. G. A. Stahl, J. Polym. Sci., Polym. Chem. Ed., 19, 371 (1981).

7. I. K. Virma and S. Patnaik, Eur. Polym. J., 12, 259 (1976).

8. T. Okano, S. Aoyagi, and I. Shinohara, Nippon Kagaku Kaishi, 161 (1976).

9. L. S. Luskin and R. J. Myers, "Encyclopedia of Polymer Science and Technology," Vol. 1, H. F. Mark, N. G. Gaylord, and Bikales, Ed., Wiley, New York, N. Y., 1964, p 246.

10. Calculated using $Q_{1}=0.8$ and $e_{1}=0.2$ from "Polymer Handbook, 2nd ed," J. Brandrup and E. H. Immergut Ed., Wiley, New York, N.Y., 1975, II-396.

11. J. Mayumi, Thesis, Nagoya Univ., Fac. of Eng., 1980.

12. K. Ito, Y. Masuda, T. Shintani, T. Kitano, and Y. Yamashita, Polym. J., 15, 443 (1983).

13. S. Yamashita, K. Shibatani, K. Takakura, and K. Imai, Kobunshi Ronbunshu, 39, 187 (1982).

14. I. K. Virma and S. Patnaik, Eur. Polym. J., 13, 175 (1977).

15. L. Lebduška, J. Sňupárek, Jr., and V. Čermák, $J$. Polym. Sci., Polym. Let. Ed., 22, 261 (1984).

16. T. Kelen and F. Tüdös, J. Macromol. Sci., Chem., A9, 1 (1975).

17. K. Ito, H. Tsuchida, A. Hayashi, T. Kitano, E. Yamada, and T. Matsumoto, Polym. $J$, to be published.

18. The peak areas (A) around $\delta 4.2-3.5$ come from the HEMA oxyethylene and LMA ester $\alpha$-methylene protons, while those (B) around $\delta 2.3-0.7$ from the other protons including the hydroxyl proton of HEMA when measured in $\mathrm{CDCl}_{3}$. (In $\mathrm{CD}_{3} \mathrm{OD}-$ $\mathrm{CDCl}_{3}$, the HEMA hydroxyl proton merged with the peak of the solvent at $\delta 4.3$.) The mole fraction of HEMA, $x$, was obtained from the ratio $A / B$ as follows:

$A / B=[4 x+2(1-x)] /[6 x+28(1-x)]$ in $\mathrm{CDCl}_{3}$,

$A / B=[4 x+2(1-x)] /[5 x+28(1-x)]$ in $\mathrm{CDCl}_{3}-\mathrm{CD}_{3} \mathrm{OD}$. 